\title{
Antimicrobial, Anticancer, Antioxidant Potential of Pyridine based Coordination Compounds: In-silico ADMET Prediction and Molecular Docking Simulations
}

\author{
S. Syed Ali Fathima, E.R. Nagarajan
}

\begin{abstract}
The novel Schiff base metal complexes were derived from the reaction of 9-anthraldehyde and 2-amino-3-hydroxypyridine and metal chlorides All the compounds were investigated by various spectral analysis. From the analysis, it is clear that compounds have square planar geometry with crystalline look. The DNA synergic studies suggest that the compounds were better DNA binder. The synthesized compounds were screened against several microbes which specified that the compounds have greater screening ability than ligand due to chelation. The anticancer activity of the synthesized compounds was also studied which revealed that the $\mathrm{Cu}(\mathrm{II})$ has greater potential rather than other compounds. The antioxidant ability display that the synthesized compounds have excellent ability to destroy the free radical than ligand. The ADMET evaluation shows that the prepared compounds hold good drug-likeness skill.
\end{abstract}

Keywords DNA synergy, Electrophoresis, Metal compounds, Square planar.

\section{INTRODUCTION}

Schiff base complexes initiate the interest of material chemists as flexible moiety owing to the viable accessibilities and structure variation [1]. They are an important category of the ligand in terms of reaction probability and chelation talent to the metal therefore compounds act as biologically active substances. In particular, any ligand carrying $(-\mathrm{CH}=\mathrm{N})$ play as 'privileged ligand' and the availability of unpaired of electrons in broadly contributes to excel its coordination effect, while exploring through the sharing of one or more donor ions with nearby azomethine group [2]. Schiff bases react to form stable compounds with common transition metal ions in various oxidation states.

Transitional metal complexes play an important role in metabolic processes and it is associated with the importance of material chemistry for the identification of diseases in clinical chemistry. In recent times, bioorganic chemists

Revised Manuscript Received on December 29, 2019.

S. Syed Ali Fathima, Department of Chemistry, Kalasalingam Academy of Research and Education, Krishnankoil-626126, Tamil Nadu, India. Email: msm.syedali@gmail.com

E.R. Nagarajan, Department of Chemistry, Kalasalingam Academy of Research and Education, Krishnankoil-626126, Tamil Nadu, India. Email: nagarajanklu@gmail.com intent on the bi-dentate ligand and their metal compounds as the main focus of their pharmacological research. An immense range of natural actions, including antimicrobial, anti-tumour, and free radical scavenger activity studies are stimulated by organic compounds $\mathrm{C}, \mathrm{N}, \mathrm{O}$ and $\mathrm{S}$ and their metal complexes [3].

Owing to their wide spectrum of biological actions, heterocyclic compounds were used in the various field. Pyridine ligands, which is utilized in inorganic chemistry with various metal and engage as an exclusive role in the preparation of biologically active substances. 2-Amino3-hydroxy pyridine is utilized as a precursor for hair colour dyes. It reacts with primary intermediates to form final dyestuff. The reaction can be accelerated by adding oxidant and followed by oxidation. This compound was used to prepare the anti-inflammatory drugs. It was used as a potential complexation agent for the spectrophotometric, polarographic and titrimetric determination for various metal ions.

In this research, the synthesis, characterization, DNA synergy, antimicrobial, antioxidant, cytotoxic studies, in-silico ADMET prediction and molecular docking of novel transition metal complexes containing Schiff base ligand obtained from 9-anthraldehyde and 2-amino-3-hydroxy pyridine are described.

\section{EXPERIMENTAL}

The materials used in this research were procured from Merck. The solvents were purchased from Sigma Aldrich.

\section{A. Synthesis of metal complexes}

The synthesis of Schiff base ligand was reported previously by us [4]. The novel complexes of the form $\left[\mathrm{ML}_{2}\right]$ in 1:2 (M:L) molar ratio were synthesized by using our premade Schiff base ligand. $0.2 \mathrm{mmol}$ of Schiff base ligand was added with an ethanolic solution of metal chloride salt $(0.1 \mathrm{mmol})$ and the resulting mixture was sonicated for $5 \mathrm{~h}$ and heated under reflux for $24 \mathrm{~h}$. The coloured precipitates were obtained. The resultant product was washed with ethanol, filtered and recrystallized. The obtained crystalline solid product was dried over anhydrous $\mathrm{CaCl}_{2}$ under

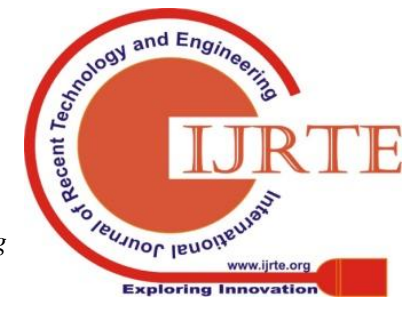


vacuum condition (Scheme 1).

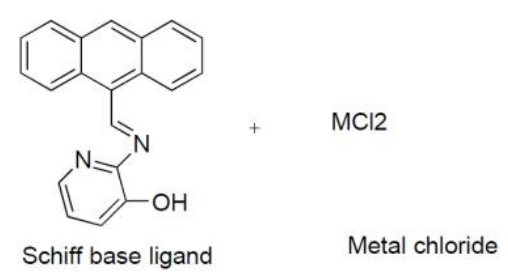

Sonocated for $5 \mathrm{~h}$

Reflux for $24 \mathrm{~h}$ / Ethanol

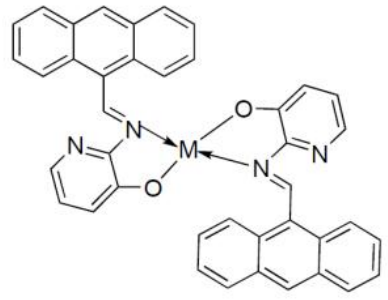

Schiff base metal complex

Where $\mathrm{M}=\mathrm{Cu}(\mathrm{II}), \mathrm{Co}(\mathrm{II}), \mathrm{Ni}(\mathrm{II})$ and $\mathrm{Zn}(\mathrm{II})$

Scheme 1. Synthesis of metal complexes.

\section{RESULTS AND DISCUSSION}

\section{A. FT IR spectra}

Vibration spectroscopy is the most important analysis to validate the structure of the synthesized compounds. In the metal compounds (-OH) peak attributed to stretching frequency has completely vanished which evidenced that the removal of a proton from $(-\mathrm{OH})$ group and chelated with central metal. Conversely, the sturdy vibration observed at $1660-1630 \mathrm{~cm}^{-1}$ in the metal complexes was allocated to the $\mathrm{CH}=\mathrm{N}$ group vibration, which was changing position into the lesser wave number by $1630-1666 \mathrm{~cm}^{-1}$ representing the chelation of $(-\mathrm{CH}=\mathrm{N})$ group to the central metal [5]. The extra peaks were observed in the low vibration from 410-420 $\mathrm{cm}^{-1}$ and 520-535 $\mathrm{cm}^{-1}$ are related with the metal-nitrogen and metal-oxygen vibrations respectively, which explain the involvement of the $\mathrm{N}$-atom of the $(-\mathrm{CH}=\mathrm{N})$ group and O-atom of the $(-\mathrm{OH})$ group of pyridine entity with the metal centre upon chelation [6]. The infrared spectrum of the Copper compound is represented in Fig. 1.

\section{B. Electronic spectra}

The UV-visible spectrum of the ligand shows double bands, the weak band around 38,910-32,258 $\mathrm{cm}^{-1}$ and strong band around 30,303-28,571 $\mathrm{cm}^{-1}$. In Schiff base metal complexes, these bands $n \rightarrow \pi^{*}$ and $\pi \rightarrow \pi^{*}$ display slight deviated by position or intensity, which signifies the chelation of ligand to the metal [7]. The ternary compounds exhibits an extra band of $\mathrm{d}-\mathrm{d}$ transition and these characteristic bands are utilized to calculate the configuration of the compounds. The spectrum of the Copper compound displays the transition band at $19047 \mathrm{~cm}^{-1}$ and it is attributed to ${ }^{2} \mathrm{~B}_{1 \mathrm{~g}} \rightarrow{ }^{2} \mathrm{~A}_{1 \mathrm{~g}}$ transition, which is the trait of absorption for square planar structure and its magnetic moment is $1.84 \mathrm{BM}$. The report revealed the $\mathrm{Cu}$ (II) has monomeric in nature. Cobalt displays a transition peak at $19417 \mathrm{~cm}^{-1}$ and this band is associated with ${ }^{1} \mathrm{~A}_{1 \mathrm{~g}} \rightarrow{ }^{1} \mathrm{~B}_{1 \mathrm{~g}}$ transition, which explains the compound possesses square planar geometry. It is extra evidenced by its magnetic moment 3.25 BM. Ni(II) compound displays a d-d band at $19305 \mathrm{~cm}^{-1}$, and designated to ${ }^{1} \mathrm{~A}_{1 \mathrm{~g}} \rightarrow{ }^{1} \mathrm{~B}_{1 \mathrm{~g}}$ transition ascribed to square planar configuration and it is also recommended by zero magnetic moment, which is the property of square planar structure. $\mathrm{Zn}(\mathrm{II})$ shows no transition peak, because of its entirely packed $\mathrm{d}^{10}$ arrangement and it revealed the INCT band at $31250 \mathrm{~cm}^{-1}$. It is additionally suggested by its zero magnetic moment. Conversely, according to its physicochemical analysis and other spectral reports, the square planar configuration is proposed for the Zinc complex. The electronic spectrum of the Copper compound is displayed in Fig. 2.

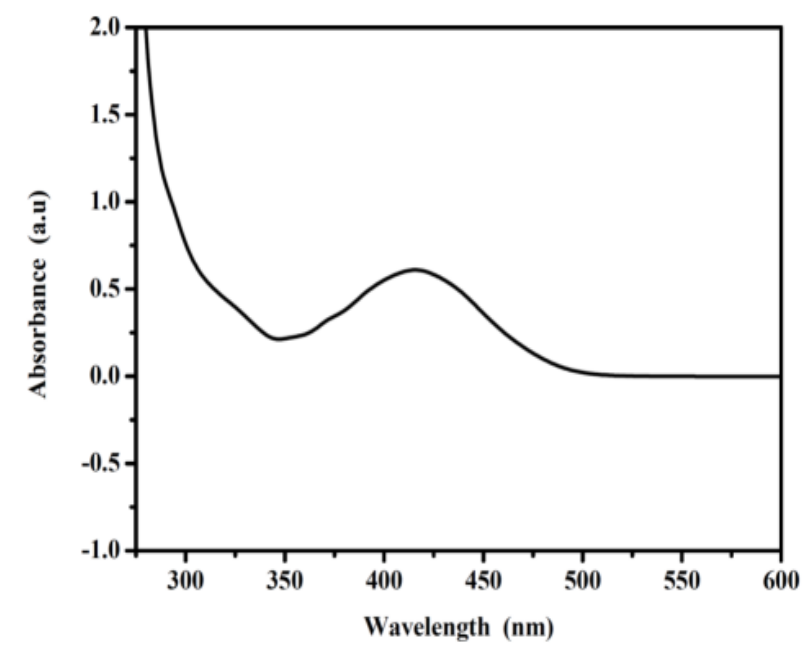

Fig. 2. Electronic spectrum of $\mathrm{Cu}$ (II) complex.

\section{Proton NMR}

The proton and ${ }^{1}$ HNMR of the synthesized Zinc compound are displayed in Fig 3.

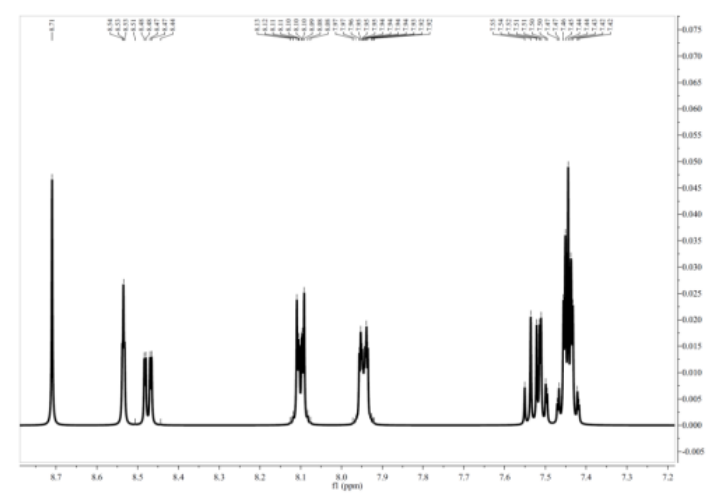

Fig. 3. ${ }^{1} \mathrm{H}$ NMR spectrum of $\mathrm{Zn}$ (II) complex.

The spectrum of the $\mathrm{Zn}$ (II) correlated to the Schiff base [4]. The compound 
produces aromatic multiplet in 7.4-8.54 ppm. The azomethine peak relocated to $8.71 \mathrm{ppm}$, which signifies the chelation of $(-\mathrm{CH}=\mathrm{N})$ to the metal centre [8]. The peak corresponds to - $\mathrm{OH}$ is completely disappeared,

Which implies that the removal of a proton from $(-\mathrm{OH})$ group and ensure the coordination.

\section{D. ${ }^{13} \mathrm{C}$ NMR}

The spectrum of the $\mathrm{Zn}$ (II) signifies the aromatic group around $118.63-158.07 \mathrm{ppm}$ and $-\mathrm{CH}=\mathrm{N}$ shifted to 161.18 ppm designates the coordination of the azomethine group to the central metal ion, but the proton owing to -OH peak has vanished and one more peak appeared for carbonyl group at $171.77 \mathrm{ppm}$, which specifies the removal of proton from -OH group and formation of carbonyl group chelated with metal centre [9].

\section{E. Mass spectra}

Mass analysis is a significant analysis commonly used for the configuration of chelated complexes [10]. The result of this analysis stands in good harmonious with the present configuration. The synthesized metal compounds $\mathrm{Cu}, \mathrm{Co}, \mathrm{Ni}$, $\mathrm{Zn}$ which produce the base peaks at $\mathrm{m} / \mathrm{z}$ 658, 653, 654, 660 $(\mathrm{M}+2)$ respectively. The mass spectrum of copper compound displays the base peak at $\mathrm{m} / \mathrm{z} 658(\mathrm{M}+1)$ which is equal to its mass of the compound. Copper compound shows the fragmentation peaks (Fig. 4) at $\mathrm{m} / \mathrm{z}$ 610, 469, 360, 298, 282, 205, 178, 128 and 78 corresponding to $\mathrm{C}_{36} \mathrm{H}_{26} \mathrm{CuN}_{4} \mathrm{O}_{2}$, $\mathrm{C}_{25} \mathrm{H}_{18} \mathrm{CuN}_{4} \mathrm{O}_{2}, \quad \mathrm{C}_{20} \mathrm{H}_{13} \mathrm{CuN}_{2} \mathrm{O}, \quad \mathrm{C}_{20} \mathrm{H}_{14} \mathrm{~N}_{2} \mathrm{O}, \quad \mathrm{C}_{20} \mathrm{H}_{14} \mathrm{~N}_{2}$, $\mathrm{C}_{15} \mathrm{H}_{11} \mathrm{~N}, \mathrm{C}_{14} \mathrm{H}_{10}, \mathrm{C}_{10} \mathrm{H}_{8}$ and $\mathrm{C}_{6} \mathrm{H}_{6}$ ions respectively. These fragment peaks in the compound highly recommended the 1:2 (M:L) ratio of the formula of the compounds. The mass spectrum of Copper complex is portrayed in Fig. 5.

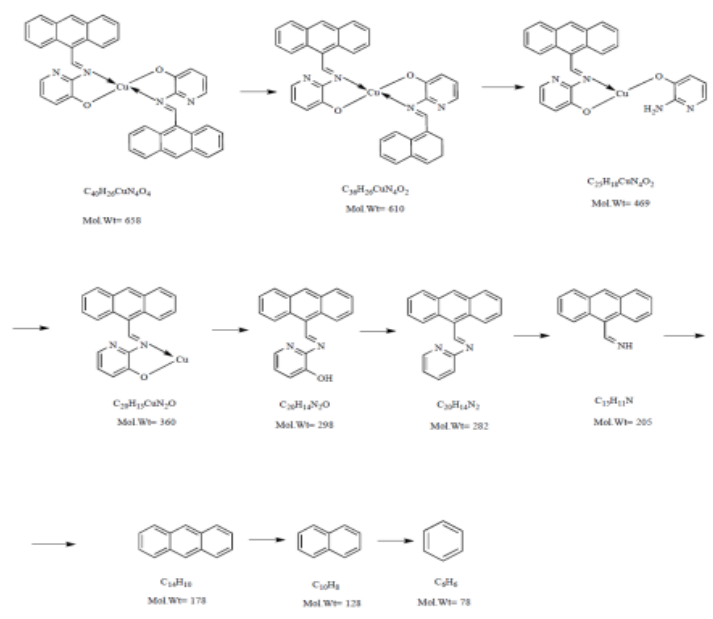

Fig. 4. Mass fragmentation pattern of $\mathrm{Cu}(\mathrm{II})$ complex.

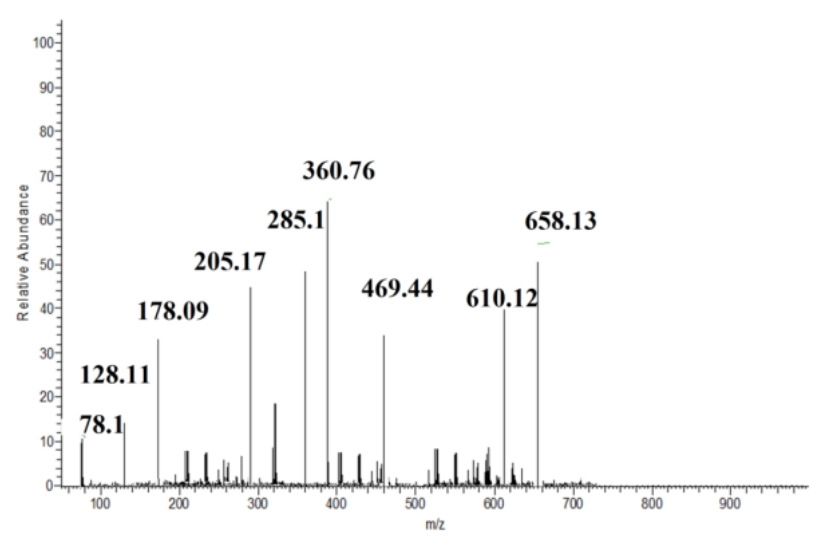

Fig. 5. ESI-MS analysis of Copper complex.

\section{F. XRD spectra}

XRD spectra have been utilized to confirm the crystalline size of the synthesized complexes. By correlating the XRD pattern of the free ligand, the metal compounds show a few new peaks, which support the complexation. The size is measured by Debye Scherer's formula:

The average crystalline size of $\mathrm{Cu}, \mathrm{Co}, \mathrm{Ni}$ and $\mathrm{Zn}$ compounds are $35,37,42,18 \mathrm{~nm}$ respectively. The XRD pattern of the Nickel compound is depicted in Fig. 6.

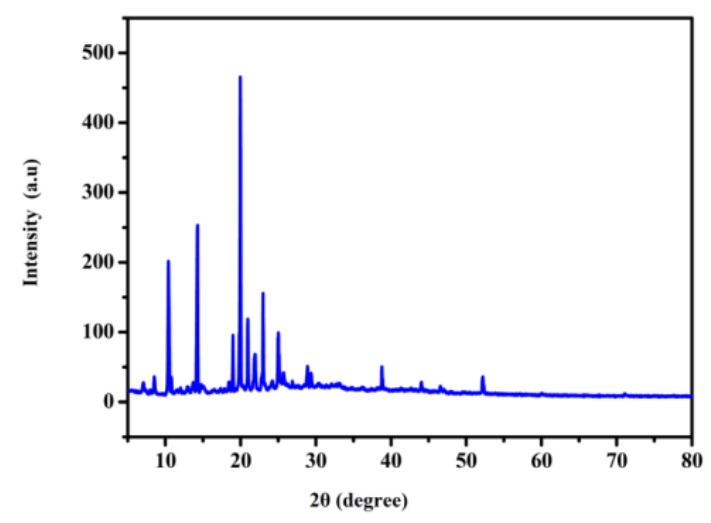

Fig. 6. Powder XRD pattern of $\mathrm{Ni}(\mathrm{II})$ complex.

\section{E. Scanning electron microscopy}

The synthesized compounds have the uniform crystalline sizes with 2-10 $\mu \mathrm{m}$. $\mathrm{Cu}, \mathrm{Co}, \mathrm{Ni}$ and $\mathrm{Zn}$ compounds possess flakes, hexagon, needle-fashioned and brick-like shapes respectively. The SEM images of the complexes are displayed in Fig. 7.
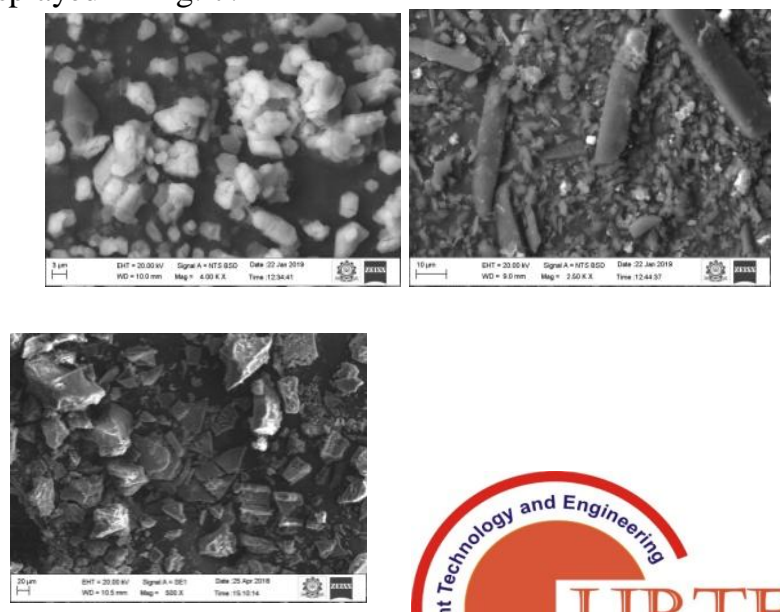

Published By:

Blue Eyes Intelligence Engineering 


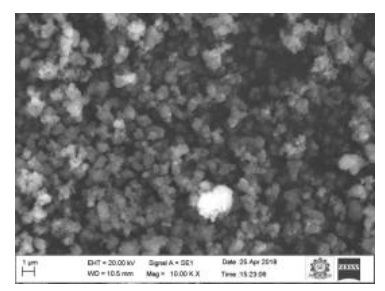

Fig. 7. SEM pictures of the metal compounds.

\section{BIOLOGICAL STUDIES}

\section{A. DNA interaction studies}

DNA binding analysis is a vital test for establishing the novel based curative medicine.

\section{B. Electronic absorption spectral titration}

UV absorption technique is the crucial one for determining the mode of binding of compound with DNA.

Upon adding of nucleic acid from 1to $24 \mu \mathrm{M}$ a significant "hyperchromic" effect of the intraligand bands at 320-350 $\mathrm{nm}$ [12]. Hypochromic effect which initiates the reduction of nucleic acid fragments, thereby denatured the configuration of DNA, while hyperchromism induces the impairment of the DNA strands owing to the $\pi \rightarrow \pi^{*}$ inter-communication among the synthesized compound and the base pair of filament through intercalation [13]. The binding mode of the Copper compound is represented in Fig. 8.

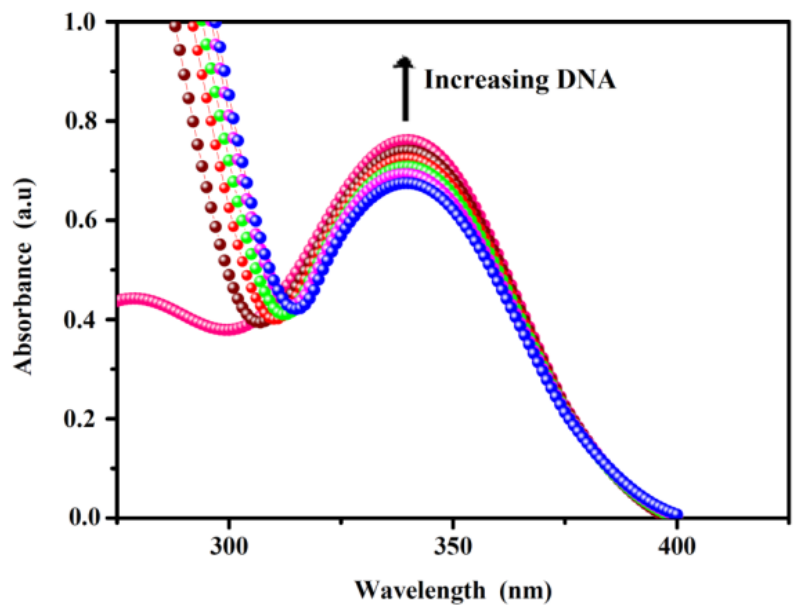

Fig. 8. DNA binding affinity of Copper compound.

\section{Hydrodynamic measurements}

The viscosity experiment is over sensitiveness to the disparity in nucleic acid length and is considered as one of the most efficient analysis to verify the interaction of the compounds with DNA. This augmentation which is initiates to enlarge the filament and base compounds are deviated at interaction sites for holding the synthesized compounds. Conversely, a tiny compound linked with DNA strand via
DNA grooves under the same condition frequently it initiate to alter the DNA viscosity.

From the value of flow ratio, the specific viscosity of the metal compounds was measured. Generally, the nucleic acid fragments get elongated by isolating the base pairs to hold the compounds, which leads to amplify the DNA viscosity while the intercalated stacking plays between the compounds with DNA [14].The reports indicates that the compound interact with nucleic acid through intercalated pathway.

\section{BIOLOGICAL EVALUATIONS}

\section{A. Antibiotic analysis}

The prepared compounds were analysed for their anti-pathogenic action with diverse concentration of solution. The data signifies that all the compounds have greater skill than the Schiff base owing to higher lipophilicity of the compounds. The enhanced capability of the metal complexes owing to the configuration and chelation leads to produce the metal compounds play more potent and introducing efficient antibiotic agents and thus to prevent the multiplication of bacteria. This enhances in the capability of the compounds because of chelation hypothesis. Chelation considerably minimizes the polarization of the metal and improves the lipophilic nature of the metal, which supports the compound penetrability via the lipid wall of the tissue wall. Copper (II) compound displays high anti-fungicide and anti-bactericide than other compounds. The difference skill of the compounds influence on the immobility of the microbial cells or the variation in the ribosomal levels. The anti-bactericidal and anti-fungicidal action of the compounds are portrayed in Figs. 9 and 10 respectively.

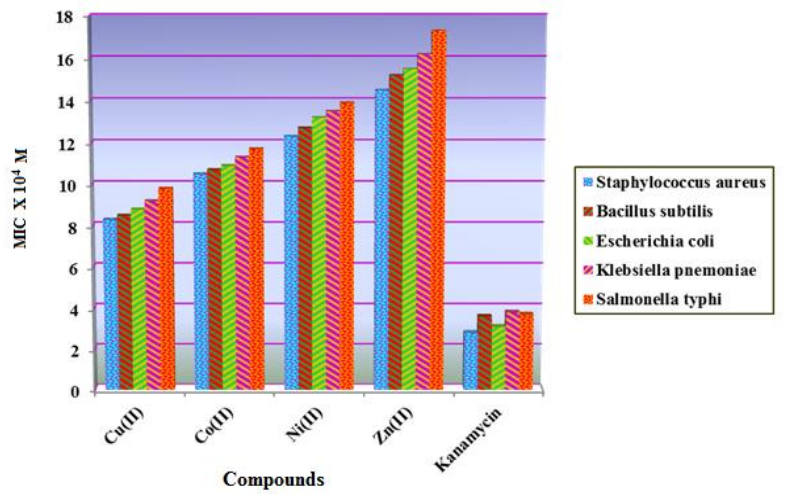

Fig. 9. The antibacterial activity of the synthesized compounds. 


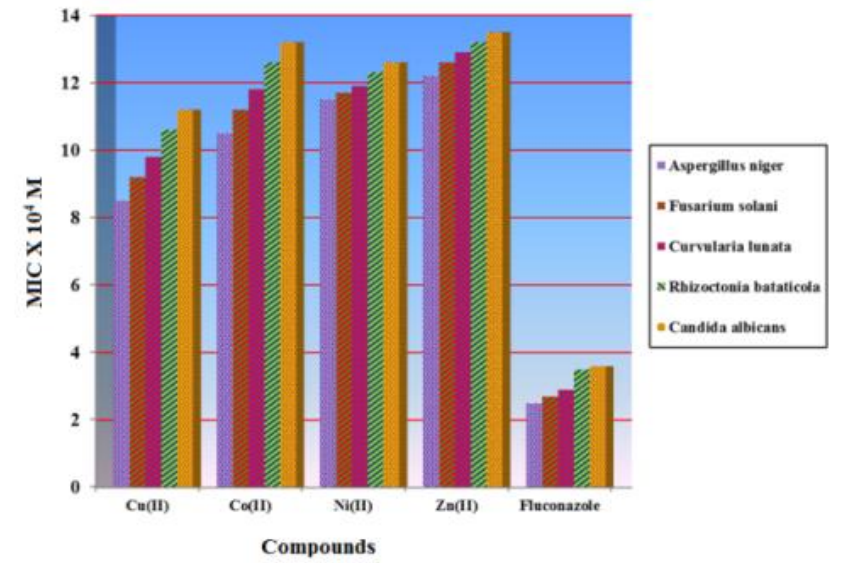

Fig. 10. The antifungal activity of the synthesized compounds.

\section{B. Antitumor action}

The in-vitro anti-carcinogenic ability was analyzed against a pair of tumour cell lines such as MCF-7 (breast cancer cell line), Hep G2 and HBL-100 (non cancerous cell line of mouse embryonic fibroblast) by MTT assay using Cisplatin as standard. The assay shows that the compounds have a greater ability and slow down the development of tumour tissue line. The reports of cell hindrance represented as $\mathrm{IC}_{50}$ data. Among these compounds, $\mathrm{Cu}$ (II) compound displays greater antitumor action correlated to remaining compounds on the proliferation of tumour cell lines due to size and ionic radius that act a unique position in the efficiency of this activity [15].

The anticancer activity of the metal complexes is portrayed in Fig. 11 .

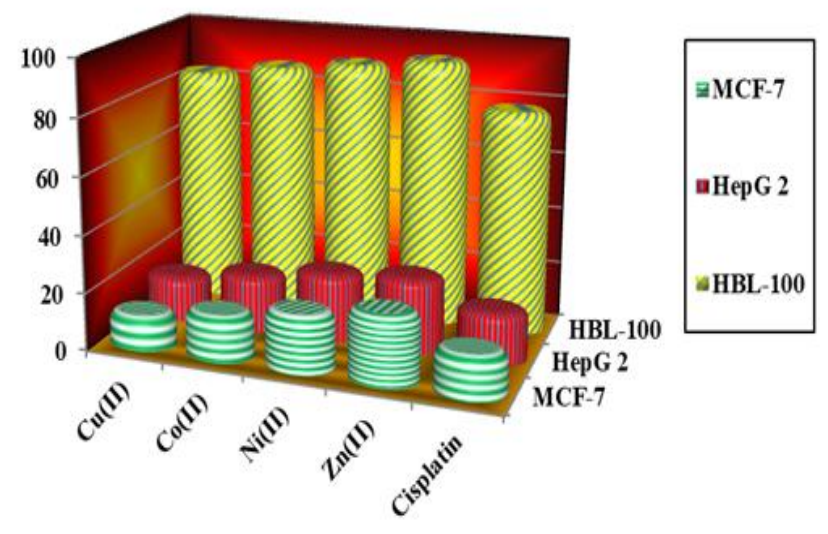

Fig. 11. The antitumor action of the synthesized compounds.

\section{Antioxidant activity}

Anti-oxidising agents are chemicals that slow down the oxidation. The data revealed that $\mathrm{Cu}$ (II) compound has good antioxidant aptitude even in minimum concentration than the other compounds. However, the scavenging effect of Schiff base boosts during complexation and multiples the scavenging talent and so to screen the living beings against different illness [16]. The scavenging action of the ternary complexes is given in Fig. 12.

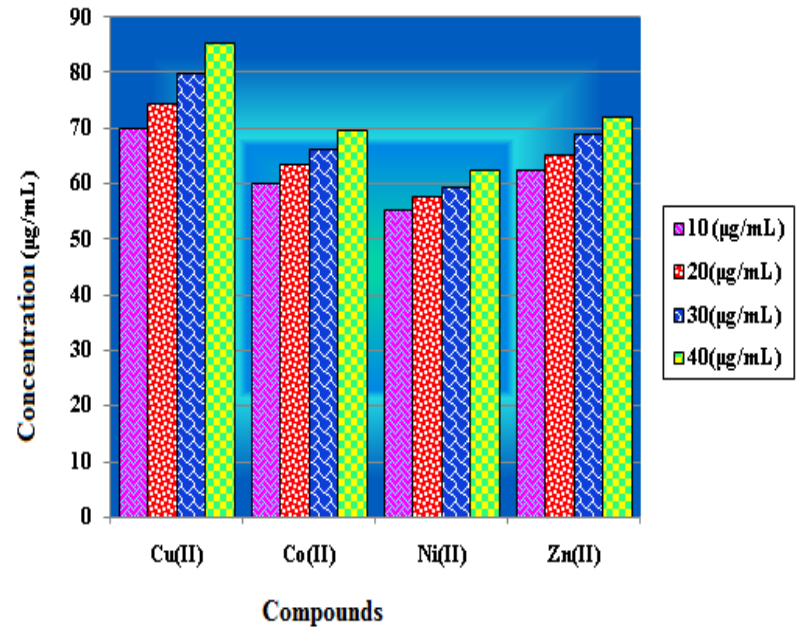

Fig. 12. Percentage of antioxidant activity of the metal complexes using Vitamin $\mathbf{C}$ as standard.

\section{COMPUTATIONAL STUDIES}

\section{A. Molecular docking}

Docking simulation is employed to authenticate the method of inter-synergy of nucleic acid with synthesized complexes [17]. This research is done by Autocock Vina software against nucleic acid and protein inhibitor is attached in Figs. 13-14. The inter-synergy of complexes with DNA was executed by the aforesaid program by DNA (PDB ID: 1BNA) and protein (PDB ID: 6Q7K) synthesized complexes interact with DNA and protein. The interaction energy of synthesized compounds with 1BNA is -368.13 , $-313.57,-334.23$ and $-326.12 \mathrm{~kJ} / \mathrm{mol}$ respectively. The binding affinity of compounds with $6 \mathrm{Q} 7 \mathrm{~K}$ was performed by a similar procedure. The interaction energy of prepared compounds with protein are -268.17,-213.43, -234.43, -226.44 and -210.12 . The result ensures that the synthesized compounds were interplay with DNA base pairs via intercalated pathway. These results are well correlated with experimental DNA binding assays.

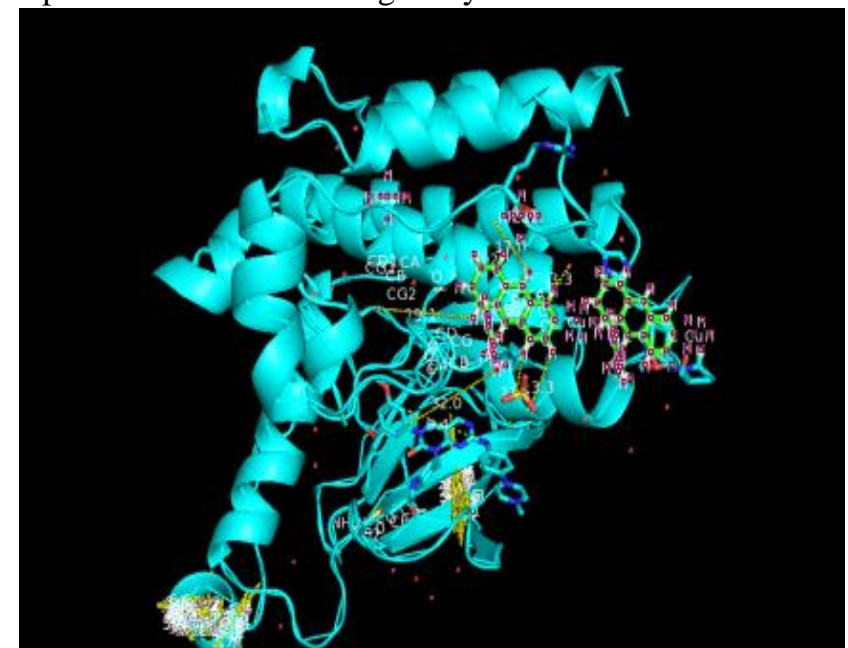

Fig. 13. The binding model of Copper complex with 6Q7K protein. 


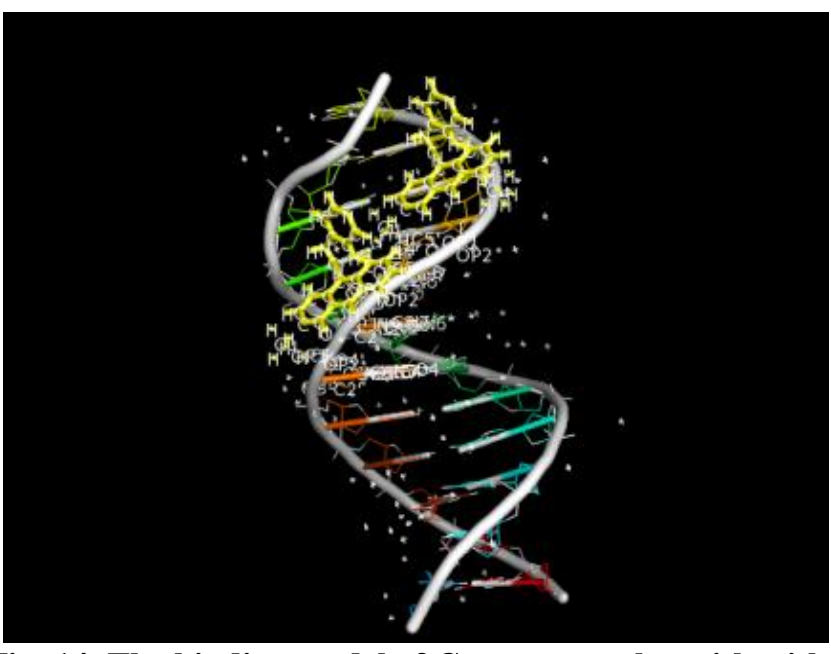

Fig. 14. The binding model of Copper complex with with DNA.

\section{B. In-silico ADMET prediction}

Simulation provides a low cost and quick passage to determine the drug like feature of the complexes. SwissAdme software is employed to calculate their bioactivity score of the prepared compounds and toxicity parameters are predicted by AdmetSAR simulation..

- $\log$ P: This is a factor to verify the hydrophobic character of the prepared compound, which influence the penetrability of the compounds throughout the metabolism of living beings. In this research, $\log \mathrm{P}$ for prepared complexes are 5.43, it signifies that the compounds have definite pervious talent during metabolic action.

- Molecular weight: The molecular weight of the prepared compounds is more than 500. By Lipinski guideline, the complexes have a modest drug-like aptitude.

- H-releasing and withdrawing capacity: The metal complexes have eight hydrogen bond acceptors and no hydrogen bond donors. Based on this rule, complexes act more stretchy and interact with active site successfully.

- TPSA: This is a general analysis factor on the H-bond required to discover cell penetrating skill. TPSA is measured by adding $\mathrm{O}, \mathrm{N}$ and attached $\mathrm{H}$ in ternary complexes. In this research, complexes possess TPSA value $68.96 \AA^{2}$ (below $140 \AA^{2}$ ), which are composed of the synthesized compounds that have good drug transportation kind and may be in favour of medicine.

- Rotatable bonds: The counting of this parameter for the compounds are eight. Therefore, they possess the suitable aptitude to intercommunicate with the biological system strongly.

- Bioactivity score prediction: The drug action of the compounds describe the positive property of drugs on living beings. The drug should be entrenched with a natural entity with proteins, enzymes, ion channels and receptors. For this research, metal compounds have a value of 0.17. According to Lipinski's rule, the compounds that have bio-scores greater than zero which implies that they have the best drug-like action.

- Toxicity assessment: Mutagenic and cancer activity diagnosed in AdmetSAR software. The evaluation of the toxicity limit as the main factor in the detection of toxic-free treatment drugs. From the software all the ternary compounds do not have any toxicity.

\section{CONCLUSION}

The current work elucidates the preparation of novel transition metal complexes from pyridine based ligand. DNA synergy studies which explained that all these metal compounds inter communicated with CT-DNA most probably by intercalated binding mode. The binding constant value of $\mathrm{Cu}(\mathrm{II})$ complex indicates that it plays as a proficient metal binder. The DNA nuclease activity of the compounds displays that all the metal compounds can break the nucleic acid strands in the presence of the oxidizing agent. The assessment of the antimicrobial activity of the compounds signifies that the screening action amplifies on complexation with metal. The docking simulation study well supported the intercalating binding mode of interaction between DNA and protein. The test of carcinogenic activity and radical scavenging test of the compounds confirmed that the complexes have more talent as a result of chelation. The drug-like explained that the compounds have greater drug-likeness skill based on various parameters calculated from software. All results ensured that the chelation and heterocyclic ligand, which leads to the efficient DNA analysis, which is the key to increasing the bio-essence of the compounds.

\section{ACKNOWLEDGMENT}

The author, S.SAF gratefully acknowledges the Kalasalingam Academy of Research and Education for offering research fellowship and necessary facilities.

\section{REFERENCES}

1. T. Rosu, S. Pasculescu, V. Lazar, C. Chifiriuc, R. Cernat, Copper(II) complexes with ligands derived from 4-amino-2,3-dimethyl-1- phenyl-3-pyrazolin-5-one:Synthesis and biological activity, Molecules, vol. 11, 2006, pp. 904-914.

2. N. S. Gwaram, H. M. Ali, M. A. Abdulla, Antibacterial evaluation of some Schiff bases derived from 2-acetyl pyridine and their metal complexes, Molecules, vol. 17 2012, pp. 5952-5971.

3. K.T. Joshi, A.M. Pancholi, K. S. Pandya, A. S. Thakar, Synthesis, characterization and antibacterial activity of novel Schiff base derived from 4-acetyl-3-methyl-1-(4'-methyl-phenyl) 2-Pyrazolin-5-one and it transition metal complexes, Int. J. Res. Chem. vol. 1, 2011, pp. 263-269.

4. S. Syed Ali Fathima, M. Mohamed Sahul Meeran, E.R. Nagarajan, Synthesis of novel (E)-2- ((anthracen-9-ylmethylene)amino)pyridin-3-ol and its transition metal complexes: Multispectral characterization, biological evaluation and computational studies J. Mol Liq. vol. 279, 2019, pp. 177-187.

5. M. M.Omar, G. G. Mohamed, A. M. M. Hindy, J. Therm. Anal. Cal., vol. 86, 2006, pp. 315-325.

6. A.D. Naik, S.M. Annigeri, U.B. Gangadharmath, V.K. Revankar, V.B Mahale, Anchoring mercapto- triazoles on dicarbonyln backbone to assemble novel binucleating, acyclic SNONS compartmental ligands, Indian J. Chem. vol. 41A, 2002 pp. 2046-2053.

7. 7. A.S. Pedrares, J. Romero, J.A.G. Vazquez, M.L. Duran, I Casanova, Electrochemical synthesis and structural characterisation of zinc, 
cadmium and mercury complexes of heterocyclic bidentate ligands (N,S). Dalton Trans., vol. 7, 2003, pp. 1379-1388.

8. E.L. Asmy A.A. Khalifa, M.E. Hassanian, Synthesis and characterization of transition metal complexes containing oxime, amido and thioamido groups. Indian J. Chem., vol 43A, 2004, pp. 92-97.

9. J.K. Ekegren, P. Roth, K. Kallstrom, T. Tarnai, P.G. Andersson, Synthesis and evaluation of N,S-compounds as chiral ligands for transfer hydrogenation of acetophenone, Org. Biomol. Chem., vol. 1, 2003, pp. 358-366.

10. T. Punniyamurthy, S.J.S. Kalra, J. Iqbal, Iodobenzene catalysed C-H amination of N-Substituted amidines using $\mathrm{m}$-Chloro per benzoic acid, Tetrahedran Lett., vol. 36, 1995, pp. 8497-8500.

11. R.K. Agarwal, I. Singh and D.K. Sharma, Synthesis, spectral, and biological properties of copper(II) complexes of thiosemicarbazones of Schiff bases derived from4-aminoantipyrine and aromatic aldehydes, Bioinorg. Chem. and Appl., vol. 1, 2006, pp. 1-10.

12. Sh. M. Morgan, M.A. Diab, A.Z. El-Sonbati, Supramolecular assembly of hydrogen bonding, ESR studies and theoretical calculations of $\mathrm{Cu}$ (II) complexes, Appl. Organometal. Chem., vol. 32, 2018, pp. 4504-4518.

13. D. Mendoza-Rayo, L.Chacon-Garcia, Oxidative homo coupling of aryl boronicacids catalysed by a 4-aminoantipyrine-Pd(II) complex, Appl. Organometal. Chem., vol. 29, 2015, pp. 439-442.

14. M. Khosro, M. Abdeshah, Syn. React. Inorg. M, Taylor and Francis, 2012.

15. S.I. Mostafa, S.A. Abd, El-Maksoud, Monatsheftefur chemie/ chemical monthly, vol. 129, 1998, pp. 455-466.

16. E.C. Zaino, R.H. Roberts, Chelation therapy in chronic iron overload,Stratton intercontinental medical book, New york 1977.

17. G.B. Bagihalli, P.G. Avaji, S.A. Patil, P.S. Badami, Synthesis, spectral, characterization, in-vitro antibacterial, antifungal and cytotoxic activities of $\mathrm{Co}(\mathrm{II}), \mathrm{Ni}(\mathrm{II})$ and $\mathrm{Cu}(\mathrm{II})$ complexes with 1,2,4- triazole Schiff bases, Eur. J. Med. Chem., vol. 43, 2008, pp. 2639-2649.

\section{AUTHORS PROFILE}

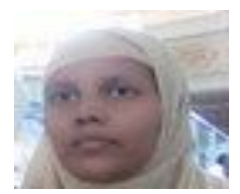

S. Syed Ali Fathima pursuing Ph.D in the area of coordination compounds, biological application and computtational simulationns at Kalasalingam Academy of Research and Education, Krishnankoil, Tamil Nadu, India.

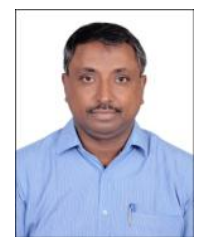

E.R. Nagarajan works as Associate Professor, Department of Chemistry, Kalasalingam Academy of Research and Education, Krishnankoil, Tamil Nadu, India. He received his $\mathrm{Ph} . \mathrm{D}$ degree at Anna University, Chennai, India. With a research in the applications of polymeric materials, co-ordination compounds, photocatalysis and electrochemical applications. 